\title{
Association between Insomnia and Depression in Tinnitus Patients
}

\author{
Su Il Kim, Tae Hyun Kim, Young Seok Byun, Ji Hyun Chung, \\ Su Jin Kim, Moon Suh Park, and Jae Yong Byun \\ Department of Otolaryngology-Head and Neck Surgery, School of Medicine, Kyung Hee University, Seoul, Korea
}

\section{이명 환자에서 수면 장애와 우울증 사이의 연관성}

김수일 · 김태현 · 변영석 · 정지현 · 김수진 · 박문서 · 변재용

경희대학교 의과대학 이비인후-두경부외과학교실

Received September 29, 2014

Revised November 11, 2014

Accepted November 17, 2014

Address for correspondence

Jae Yong Byun, MD, PhD

Department of Otolaryngology-

Head and Neck Surgery,

School of Medicine,

Kyung Hee University,

892 Dongnam-ro, Gangdong-gu,

Seoul 134-727, Korea

Tel $+82-2-440-6237$

Fax $+82-2-440-6296$

E-mail otorhino512@naver.com
Background and Objectives About one third of all people experience tinnitus in their life And insomnia is the second most common symptom in tinnitus patients, following hearing disturbance. The aim of this study was to define the influence of insomnia on the clinical features of tinnitus patients and to assess the relation of tinnitus to insomnia and depression.

Subjects and Method The consecutive 197 patients with tinnitus were enrolled from May 2012 to May 2013 for this study. All patients with tinnitus filled out the following questionnaire, Visual Analogue Scale, Tinnitus Handicap Inventory (THI), Beck Depression Inventory (BDI), and Pittsburgh Sleep Quality Index (PSQI) for evaluating clinical features of tinnitus patients. Also we examined pure tone audiometry and tinnitogram for evaluating audiologic characteristics. Results When the insomnia was defined as more than five scores in PSQI, 46 of 197 patients had insomnia. Loudness of tinnitus was significantly higher in the tinnitus patients with insomnia group when compared to those of the tinnitus without insomnia group ( $p=0.018)$. The score of THI and BDI were significantly higher in the tinnitus with insomnia group, too $(p=0.003$, $<0.001$, respectively). A strong correlation $(\mathrm{r}=0.616, p<0.001)$ was shown between THI score and BDI score in both groups.

Conclusion It appears, due to the high possibility that depression and insomnia are related in tinnitus patients with insomnia, that proper evaluations about sleep disturbance and depression of tinnitus patients are necessary to produce better therapeutic results.

Korean J Otorhinolaryngol-Head Neck Surg 2015;58(5):313-7

Key Words Depression · Insomnia - Tinnitus.

\section{서 론}

이명은 외부의 소리 자극 없이 신체 내에서 발생한 소리를 귀에서 감각하는 현상을 일컫는 용어로 크게 객관적 이명과 주관적 이명으로 나뉜다. 원인을 확인하여 이에 대해서 치료 가 가능한 객관적 이명과 달리 이명의 대부분을 차지하는 주 관적 이명은 달팽이관과 청신경계 문제 외에 다른 원인이 발 견되지 않는 경우가 대다수여서 치료가 어렵다.

인구의 약 3 분의 1 에서 일생에 한 번 이상 이명을 경험하며,
성인 인구의 8 15\%에서 이명 때문에 불편감을 느끼는 것으로 알 려져 있다. 그리고 약 5\%에서는 치료를 필요로 하는 심한 이명 을 느끼며, 1 5\%에서는 일상 생활에 방해가 되는 정신적인 괴 로움이 발생할 수 있다고 한다. 국내에서는 약 $20 \%$ 의 환자가 이명을 경험하는 것으로 나타나고 있으며, 이들 중 $26.17 \%$ 가 일 상 생활에 불편감을 호소한다고 보고된 바 있다. ${ }^{1-4)}$ 일부 이명 환 자들에서는 이명과 함께 짜증, 괴로움이 발생하고, 수면 장애, 집중력 저하, 정신신체적 및 대인관계의 문제 등으로 심각한 기 능의 저하를 겪게 된다.5,6) 그중 불면증은 이명 환자들에서 난 
청에 이어 2번째로 자주 동반되는 증상으로 알려져 있다. ${ }^{7}$

이명 환자들에서 수면 장애의 유병률은 25\%에서 $60 \%$ 까지 보고되고 있다. ${ }^{8-10)}$ 이명에 동반되는 수면 장애는 서로 상호작 용에 의해 나타날 수 있는데, 그 이유로 취침 시 조용한 상태에 서는 주변 소음에 의해 차폐(masking) 효과가 줄어들게 되어 이명을 느끼는 것이 증가하게 되는 것을 들 수 있다. ${ }^{11)}$ 또한 만 성 이명 환자들의 우울이 수면 장애와 유의한 상관관계가 있 으며,') 이명의 심한 정도와 수면 장애가 연관성이 있는 것으로 확인되었다. ${ }^{12)}$ 그리고 수면 장애가 이명과 관련된 괴로움의 유 발 인자 및 예측 변수로 제시되기도 하였다. ${ }^{13,14)}$

하지만 이명과 수면 장애에 대한 연구는 부족한 실정으로, 이명과 수면 장애의 상호 연관성에 대한 병태생리학적인 기전 에 대해서도 정확히 알려지지 않았고, 이명에 대한 치료가 수 면 장애에 어떤 영향을 미치는지도 명확하지 않다. 특히 아직 까지 국내에서는 이명 환자에서 수면과 우울증이 서로 어떠 한 상관관계가 있는지에 대해서는 자료가 아직 부족한 상태이 다. 따라서 본 연구에서는 이명만 있는 군과 이명과 불면증을 동반하는 군 간의 임상적 차이를 비교해 보았으며, 이명 환자 들에서 이명 및 수면에 관한 설문지와 같이 우울에 대한 설문 지도 조사하여 각각의 연관 관계를 알아보았다.

\section{대상 및 방법}

\section{대 상}

2012년 5월부터 2013년 5월까지 주관적 이명을 주소로 내 원한 환자들을 대상으로 하였다. 신경 및 정신 의학적 질환의 과거력이 있는 환자들은 제외하였으며, 또한 급성 외이 및 중 이 질환이나 다른 원인에 의해 이명이 발생하는 경우, 즉 객관 적 이명으로 추정되는 경우도 제외하였다. 이 중 설문지에 모 두 응답해 준 197 명의 환자들을 대상으로 분석하였다.

Pittsburgh Sleep Quality Index(PSQI)를 이용해 이명 환자 들의 수면 장애 정도를 알아보았고, 그 총점이 5점 초과인 경 우를 이명과 불면증을 동반하는 군으로, 5점 이하인 경우를 이명만 있는 군으로 분류하였다. ${ }^{15)}$ 두 군 간 임상적 특성의 차 이를 알아보기 위해 환자들의 나이, 성별, 이명의 측별 위치 및 이환 기간을 알아보았다. 이명의 측별 위치는 일측성과 양 측성으로 분류하여 확인하였으며, 이환 기간은 6 개월 미만과 6 개월 이상으로 분류하였다. 두 군 간 청각학적 특성을 알아 보기 위해, 순음청력검사(pure tone audiometry)와 이명도 검 사(tinnitogram)를 시행하여 청력 및 이명의 주파수와 크기의 차이를 비교하였다.

불면증의 동반 여부에 따른 이명이 일상에 미치는 정도를 알 아보기 위해, Visual Analogue Scale(VAS), Tinnitus Handi- cap Inventory(THI), Beck Depression Inventory(BDI)를 설문 조사하였다.

\section{설문지}

$\mathrm{THI}$ 는 총 25문항으로 되어 있으며, 기능 하위 척도(Functional Subscale; 11문항), 정서 하위 척도(Emotional Subscale; 9문항), 그리고 재앙화 하위 척도(Catastrophic Subscale; 5 문항)로 구성되어 있다. 각각의 항목은 0점(아니다), 2점(가끔 그렇다), 4점(그렇다)으로 점수를 기록하게 하여 총점(0 100 점)을 구한 후 0 16점은 정상, 18 36점은 경도, 38 56점은 중 등도, 58점 이상은 이명에 의해 심한 장애를 가지는 것으로 판 정한다. 본 연구에서는 이명 환자에게 THI 설문지를 통하여 이명의 주관적인 불편감을 확인하였다.

$\mathrm{BDI}$ 는 우울과 관련된 태도, 행동, 그리고 증상을 포함하는 21 개의 항목을 포함하며, 이를 확인함으로써 이명 환자들의 주관적인 우울에 대한 정도를 알아보고자 하였다.

PSQI는 지난 1 개월간의 주관적인 수면의 질을 평가하는 도 구이다. PSQI는 7개의 하위요인을 포함하는 19 개 항목으로 구 성되어 있다. $\mathrm{PSQI}$ 의 총점 5점을 기준으로, 5점 이하일 경우 를 불면증이 동반되지 않은 것으로, 5 점 초과를 불면증이 동 반된 것으로 판단하였다.

\section{청각학적 검사}

순음청력기기는 ORBITER 922 Version 2(Madsen, Denmark)를 사용하였고, 이명 환자들의 주파수 별로 $0.25,0.5$, $1,2,4$, 그리고 $8 \mathrm{kHz}$ 에서 양측의 기도 및 골도 청력 역치를 확인하였다. 평균 청력은 4 분법을 이용하여 계산하였으며, 정 상 청력은 양측에서 평균 청력이 $25 \mathrm{~dB}$ 미만의 경우로 하였고, 감각신경성 난청은 이명이 있는 귀의 평균 청력이 $40 \mathrm{~dB}$ 이상 이면서, 기도와 골도 청력의 차이가 $10 \mathrm{~dB}$ 보다 적은 경우로 하 였다. 그리고 고주파수 난청의 경우는 다른 주파수에서는 정 상 청력을 보이면서, $8 \mathrm{kHz}$ 에서만 $40 \mathrm{~dB}$ 이상을 보이는 경우 로 하였다. 또한 이명도 검사를 통하여, 각 환자들의 이명의 크 기(decibel sensory level, dB SL)와 주파수(kHz)를 확인하 였다.

\section{통계적 분석}

이명만 있는 군과 이명과 불면증을 동반하는 군 간의 임상학 적 특징과 $\mathrm{THI}, \mathrm{BDI}$ 를 서로 비교하였으며, 이는 Mann-Whitney U test 및 $\chi^{2}$-test를 통하여 알아보았다. 두 군에서 주관 적인 수면 질 측정을 위해 네 가지 구획에 대한 분포 비율 및 순음청력 검사 결과를 Fisher's exact test for count data를 통하여 비교해 보았다. 그리고 이명도 검사를 통해 얻은 이명 
의 평균 크기와 주파수의 차이를 각각 independent t-test 및 $\chi^{2}$-test를 통하여 알아보았다. VAS, THI, BDI, PSQI 상관관 계를 확인하기 위해, 각 수치 간의 Pearson's correlation coefficient를 알아보았다. $p<0.05$ 의 유의성 기준으로 통계적 검 증을 시행하였으며, SPSS(version 18.0, SPSS Inc., Chicago, $\mathrm{IL}, \mathrm{USA})$ 를 사용하였다.

\section{결 과}

본 연구는 주관적 이명을 가지는 환자 197 명을 대상으로 하 였으며, 이명만 있는 군이 151 명, 이명과 불면증을 동반하는 군이 46명이었다. 두 군의 나이, 성별, 이명의 측별 위치 및 이
환 기간, $\mathrm{VAS}$ 는 두 군 간에 유의한 차이가 없었으나, $\mathrm{THI}(p=$ $0.003)$ 와 $\mathrm{BDI}(p<0.001)$ 는 이명과 불면증을 동반하는 군에 서 의미 있게 높은 것으로 확인되었다(Table 1). 수면에 대한 주관적인 접근으로 4개의 문항을 각각 4개의 구획으로 나누 어 각 구획에 분포하는 비율을 확인해본 결과, 4 가지 문항 모 두에서 두 군 간의 통계학적 유의한 차이가 있는 것으로 나타 났다 $(p<0.001)$ (Table 2).

순음청력검사 결과에서 정상 청력, 감각신경성 난청, 그리고 고주파수 난청의 비율은 유의한 차이가 없었다. 이명도 검사 를 통해 이명의 주파수와 크기를 비교해본 결과, 주파수에서 는 유의한 차이가 없었으나, 이명의 크기는 이명과 불면증을 동반하는 군에서 $11.81 \pm 6.25 \mathrm{~dB}$ SL로 이명만 있는 군의 8.51

Table 1. Clinical characteristics in tinnitus patients with or without insomnia

\begin{tabular}{lccc}
\hline & Tinnitus only $(\mathrm{n}=151)$ & Tinnitus with insomnia $(\mathrm{n}=46)$ & $\mathrm{p}$-value \\
\hline Age (year) & $52.63 \pm 13.32$ & $52.73 \pm 14.25$ & 0.970 \\
Sex (male/female) & $81 / 70$ & $23 / 23$ & 0.665 \\
Location ( $\mathrm{n}, \%)$ & & & 0.145 \\
$\quad$ Unilateral & $106(70.2)$ & $27(58.7)$ & $19(41.3)$ \\
$\quad$ Bilateral & $45(29.8)$ & & 0.642 \\
Duration (n, \%) & $47(31.1)$ & $16(34.8)$ & $30(65.2)$ \\
$\quad<6$ month & $104(68.9)$ & $6.11 \pm 2.49$ & 0.235 \\
$\quad \geq 6$ month & $5.55 \pm 2.23$ & $58.92 \pm 28.25$ & $0.003^{*}$ \\
VAS & $42.30 \pm 25.72$ & $15.15 \pm 11.18$ & $<0.001^{*}$ \\
THI & $8.07 \pm 7.10$ & & \\
BDI & & & \\
\hline
\end{tabular}

$* p<0.05$. VAS: Visual Analogue Scale, THI: Tinnitus Handicap Inventory, BDI: Beck Depression Inventory

Table 2. Subjective sleep assessments in tinnitus patients with or without insomnia

\begin{tabular}{|c|c|c|c|}
\hline & Tinnitus only $(n=151)$ & Tinnitus with insomnia $(n=46)$ & $p$-value \\
\hline Sleep latency (minutes) & & & $<0.001$ \\
\hline$\leq 15$ & $65(43.0 \%)$ & $8(17.4 \%)$ & \\
\hline $16-30$ & $53(35.1 \%)$ & $9(19.6 \%)$ & \\
\hline $31-60$ & $18(11.9 \%)$ & $17(37.0 \%)$ & \\
\hline$\geq 61$ & $15(9.9 \%)$ & $12(26.1 \%)$ & \\
\hline Sleep duration (hours) & & & $<0.001$ \\
\hline$>7$ & $53(35.1 \%)$ & $2(4.3 \%)$ & \\
\hline $6-7$ & $62(41.1 \%)$ & $3(6.5 \%)$ & \\
\hline $5-6$ & $27(17.9 \%)$ & $13(28.3 \%)$ & \\
\hline$<5$ & $9(6.0 \%)$ & $28(60.9 \%)$ & \\
\hline Hours asleep/hours in bed & & & 0.001 \\
\hline$\geq 0.85$ & $68(45.0 \%)$ & $11(23.9 \%)$ & \\
\hline $0.75-0.84$ & $67(44.4 \%)$ & $19(41.3 \%)$ & \\
\hline $0.65-0.74$ & $8(5.3 \%)$ & $9(19.6 \%)$ & \\
\hline$<0.65$ & $8(5.3 \%)$ & $7(15.2 \%)$ & \\
\hline Number of awakenings (per week) & & & $<0.001$ \\
\hline 0 & $54(35.8 \%)$ & $5(10.9 \%)$ & \\
\hline 1 & $27(17.9 \%)$ & $3(6.5 \%)$ & \\
\hline 2 & $33(21.9 \%)$ & $5(10.9 \%)$ & \\
\hline$\geq 3$ & $27(24.5 \%)$ & $33(71.7 \%)$ & \\
\hline
\end{tabular}


Table 3. Audiologic characteristics in tinnitus patients with or without insomnia

\begin{tabular}{|c|c|c|c|}
\hline & Tinnitus only $(n=151)$ & Tinnitus with insomnia $(n=46)$ & $p$-value \\
\hline \multicolumn{4}{|l|}{$\overline{\text { PTA }}$} \\
\hline Normal hearing & $80(53.0 \%)$ & $23(50.0 \%)$ & 0.723 \\
\hline SNHL & $45(29.8 \%)$ & $12(26.1 \%)$ & 0.627 \\
\hline High tone HL & $16(10.6 \%)$ & $4(8.7 \%)$ & 0.709 \\
\hline \multicolumn{4}{|l|}{ Tinnitogram } \\
\hline Pitch & & & 0.101 \\
\hline$\leq 2 \mathrm{kHz}$ & $43(28.5 \%)$ & $19(41.3 \%)$ & \\
\hline$>2 \mathrm{kHz}$ & $108(71.5 \%)$ & $27(58.7 \%)$ & \\
\hline Loudness (dB SL) & $8.51 \pm 6.60$ & $11.81 \pm 6.25$ & $0.018 *$ \\
\hline
\end{tabular}

Table 4. Correlations of the VAS, THI, BDI, and PSQI score in tinnitus patients

\begin{tabular}{lcccc}
\hline & VAS & THI & BDI & PSQI \\
\hline VAS & - & $0.549^{*}$ & $0.393^{*}$ & 0.078 \\
THI & $0.549^{*}$ & - & $0.616^{*}$ & $0.292^{*}$ \\
BDI & $0.393^{*}$ & $0.616^{*}$ & - & $0.464^{*}$ \\
PSQI & 0.078 & $0.292^{*}$ & $0.464^{*}$ & - \\
\hline
\end{tabular}

*statistically significant correlation. VAS: Visual Analogue Scale, THI: Tinnitus Handicap Inventory, BDI: Beck Depression Inventory, PSQI: Pittsburgh Sleep Quality Index

$\pm 6.60 \mathrm{~dB}$ SL보다 유의하게 높게 나타났다( $p=0.018$ )(Table 3). 전체 환자 197명을 대상으로 VAS, THI, BDI, PSQI에서 각 각의 상관관계를 확인해 보았으며, VAS와 PSQI 간의 상관관 계를 제외한 나머지 설문 결과는 각각 서로 의미 있는 양의 상 관관계를 보이는 것으로 나타났다. 특히 $\mathrm{THI}$ 와 $\mathrm{BDI}$ 의 상관 관계(r=0.616, $p<0.001)$ 가 강하게 나타났다(Table 4).

\section{고 찰}

이명 환자에는 많은 수의 노인 인구가 포함되어 있다. 2008 년 국내 이명 환자의 비율을 살펴볼 때, 총 이명 환자에서 60 대에서 약 $14.6 \%, 70$ 세 이상에서 약 $11.7 \%$ 의 비율을 보였다. ${ }^{4)}$ 이는 65 세 이상의 노인에서는 다른 이명 환자와는 다르게 노 인의 특성으로 인한 수면 및 우울 장애가 더 빈번히 나타날 수 있다는 점을 고려할 때 높은 노인의 비율이 본 연구의 결과에 영향을 미쳤다는 점을 무시할 수는 없다. 본 연구에서는 신경 정신적 질환이 있는 대상 및 객관적 이명으로 추정되는 대상 을 제외하였을 때 나이 분포는 24세에서 73세까지 있었으며, 65세 이상 노인도 총 4명 포함되었으나 또 다른 문제인 통계적 선택 오류를 배제하기 위해 같이 분석하였다.

본 연구를 통해 이명에 불면증이 동반되는 경우에 THI와 $\mathrm{BDI}$ 가 의미 있게 높게 나타나는 것을 확인할 수 있었다. 그리 고 $\mathrm{THI}, \mathrm{BDI}, \mathrm{PSQI}$ 는 각각에 대하여 뚜렷한 양의 상관관계를 보이고 있었다. 따라서 주관적인 수면의 질을 확인하는 PSQI
는 THI와 BDI와 관련이 있으며, 불면증이 있는 이명 환자의 경 우 이명 및 우울이 더 심하게 나타나는 것을 알 수 있었다. 이전 연구들에서도 이명이 심할수록 불면증을 동반할 가능성이 높은 것으로 보고하였고, ${ }^{19,12}$ 불면증과 우울 사이의 의미 있는 상관관계를 보고한 연구도 있었다." 즉, 지금까지 연구에서 수면과 이명의 관계, 수면과 우울의 관계에 대해서는 많이 언급되어 왔으나, 국내에서 수면과 이명, 우울을 같이 연관지 어 이들 상호간의 관계에 대해서는 언급한 바가 없어 본 연 구에서는 이명과 수면, 우울, 불안에 대해 같이 평가도구를 이용하여 조사하였으며, 그 결과 이명 환자의 일차 진료 시 위 항목들의 동반 여부에 대해 함께 확인하는 것이 진단 및 치료 에 중요한 역할을 한다고 생각해볼 수 있었다.

본 연구에서 불면증이 동반된 이명 환자들의 주관적인 수 면의 척도를 확인하였을 때 이명만 있었던 환자들보다 수면 잠복기, 수면 기간, 수면의 효율 등의 항목에서 좋지 않은 결 과를 보였다. 이명 환자군과 대조군 사이의 수면 일지를 통 하여 주관적 수면의 차이에 대해 알아본 다른 연구에서도 이 명 환자는 정상인에 비해 수면 기간, 수면의 질 등의 항목에서 좋지 않은 결과를 보였던 바 있다. ${ }^{16)}$ 이를 종합해 보면 이명 환 자에게 불면증이 동반될 경우, 수면에 관한 전반적인 주관적 요소에 대해 환자가 더욱 불편하게 느끼고 있음을 알 수 있 었다. 이처럼 대부분의 연구들이 이명과 수면에 대한 주관적 수면 장애를 연구하였으나, 이명 환자에게 객관적 수면의 평 가를 위해 수면다원검사를 시행한 연구들도 있었다. 그 결과 비급속 안구 운동 수면(non-rapid eye movement sleep) 동안, 뇌의 동기화(brain synchronization), 회복성 수면(restorative sleep) 및 수면의 깊이에 연관된 델타파 영역(delta frequency band)의 스펙트럼 파워(spectral power)가 낮을수록 수면의 장애를 더 호소하는 것으로 보고된 바 있다. ${ }^{16)}$

또한 본 연구에서 청각학적 특성이 불면증에 미치는 영향 을 알아본 결과, 이명도 검사에서 이명의 크기가 불면증을 동 반한 이명 환자에서 의미 있게 높게 나타났으며, 이명의 주파 
수 및 청력에서는 차이가 없었다. 이전의 연구들에서도 불면 증을 보이는 군에서 순음청력검사 결과가 불면증을 동반하 지 않는 군과 의미 있는 차이가 없다고 보고된 바 있으며, 이명 의 크기와 불면증이 상관관계가 있음을 보고한 연구가 있어, ${ }^{12)}$ 이명에 동반되는 불면증은 청력의 저하나 이명의 주파수보다 는 이명의 크기에 영향을 받는 것으로 생각된다.

이명에 동반된 불면증의 치료에 대한 이전 연구들에 따르면, 멜라토닌(melatonin)의 사용이 이명과 수면의 호전에 관계가 있다고 보고된 바 있으며, ${ }^{17)}$ 불면증이 우울의 여부와 상관없이 이명 환자에서 괴로움의 중요한 요소이기 때문에 적절한 항우 울 치료에 의해 불면증이 대부분 호전을 보였다는 보고도 있 었다. ${ }^{18)}$ 또한 약물 치료 이외에 불면증 환자들의 첫 번째 치료 로 시작하는 인지행동치료(cognitive behavioral therapy)가 이 명 환자에 도움이 될 수 있다고 알려져 있으며, 이러한 인지행 동치료가 이명과 연관된 괴로움을 줄여주는 것에 효과가 있는 것으로 보고된 바 있다. ${ }^{19}$

여기서는 불면증 유무에 따른 이명 환자의 내원 당시 임상 적 특성, 특히 청각학적 특성과 함께 여러 설문지를 통하여 이명, 우울, 불안, 수면 등의 상관관계를 밝히고자 하는 데에 초점을 두었기 때문에, 각 군에 대해서 어떤 치료가 더 효과 가 있는지에 대해서는 전향적 방식으로 분석하지 않았다. 하 지만 이명에서 불면증이 동반되면 우울 척도가 같이 올라가 며 이들이 서로 상관관계를 가지는 것으로 볼 때 치료 역시 이 명 외 다른 증상에 대해서도 다각적으로 접근하여 시행될 필요 가 있을 것으로 사료된다.

\section{REFERENCES}

1) Meikle M, Taylor-Walsh E. Characteristics of tinnitus and related observations in over 1800 tinnitus clinic patients. J Laryngol Otol Suppl 1984;9:17-21.

2) Heller AJ. Classification and epidemiology of tinnitus. Otolaryngol Clin North Am 2003;36(2):239-48.
3) Erlandsson SI, Holgers KM. The impact of perceived tinnitus severity on health-related quality of life with aspects of gender. Noise Health 2001;3(10):39-51.

4) Cho YS, Choi SH, Park KH, Park HJ, Kim JW, Moon IJ, et al. Prevalence of otolaryngologic diseases in South Korea: data from the Korea national health and nutrition examination survey 2008. Clin Exp Otorhinolaryngol 2010;3(4):183-93.

5) Laurikainen E, Johansson R, Akaan-Penttilä E, Haapaniemi J. Treatment of severe tinnitus. Acta Otolaryngol Suppl 2000;543:77-8.

6) Rizzardo R, Savastano M, Maron MB, Mangialaio M, Salvadori L. Psychological distress in patients with tinnitus. J Otolaryngol 1998; 27(1):21-5.

7) Asplund R. Sleepiness and sleep in elderly persons with tinnitus. Arch Gerontol Geriatr 2003;37(2):139-45.

8) Crönlein T, Langguth B, Geisler P, Hajak G. Tinnitus and insomnia. Prog Brain Res 2007;166:227-33.

9) Alster J, Shemesh Z, Ornan M, Attias J. Sleep disturbance associated with chronic tinnitus. Biol Psychiatry 1993;34(1-2):84-90.

10) Sanchez L, Stephens D. Survey of the perceived benefits and shortcomings of a specialist tinnitus clinic. Audiology 2000;39(6): 333-9.

11) Drake CL, Roehrs $T$, Roth T. Insomnia causes, consequences, and therapeutics: an overview. Depress Anxiety 2003;18(4):163-76.

12) Folmer RL, Griest SE. Tinnitus and insomnia. Am J Otolaryngol 2000; 21(5):287-93.

13) Holgers KM, Erlandsson SI, Barrenäs ML. Predictive factors for the severity of tinnitus. Audiology 2000;39(5):284-91.

14) Langenbach M, Olderog M, Michel O, Albus C, Köhle K. Psychosocial and personality predictors of tinnitus-related distress. Gen Hosp Psychiatry 2005;27(1):73-7.

15) Aloba OO, Adewuya AO, Ola BA, Mapayi BM. Validity of the Pittsburgh Sleep Quality Index (PSQI) among Nigerian university students. Sleep Med 2007;8(3):266-70.

16) Hébert S, Fullum S, Carrier J. Polysomnographic and quantitative electroencephalographic correlates of subjective sleep complaints in chronic tinnitus. J Sleep Res 2011;20(1 Pt 1):38-44.

17) Megwalu UC, Finnell JE, Piccirillo JF. The effects of melatonin on tinnitus and sleep. Otolaryngol Head Neck Surg 2006;134(2):210-3.

18) Dobie RA, Sakai CS, Sullivan MD, Katon WJ, Russo J. Antidepressant treatment of tinnitus patients: report of a randomized clinical trial and clinical prediction of benefit. Am J Otol 1993;14(1):18-23.

19) Andersson G, Porsaeus D, Wiklund M, Kaldo V, Larsen HC. Treatment of tinnitus in the elderly: a controlled trial of cognitive behavior therapy. Int J Audiol 2005;44(11):671-5. 